\title{
Synthesis and Biological Activities of some Pyrimidine derivatives: (A-Review)
}

\author{
NADIA ALI AHMED ELKANZI ${ }^{1,2}$ \\ ${ }^{1}$ Chemistry Department, College of Science, Jouf University, P.O. Box: 2014, Sakaka, Saudi Arabia. \\ 2Department of Chemistry, Faculty of Science, Aswan University, P.O. box 81528, Aswan, Egypt. \\ *Corresponding author E-mail: kanzi20@yahoo.com \\ http://dx.doi.org/10.13005/ojc/360602
}

(Received: September 01, 2020; Accepted: November 17, 2020)

\begin{abstract}
Nitrogen containing synthetically and biologically important heterocyclic ring system namely pyrimidine possess both biological and pharmacological activities and defend as aromatic six heterocyclic with 1 and 3 nitrogen atom in ring. Preparation of pyrimidine via different methods offer its importance in fields of medicinal chemistry and Chemistry. Pyrimidines and their derivatives act as anti-inflammatory, anti-malaria, anti-tumor, cardiovascular agents, anti-neoplastic, anti-tubercular, anti-HIV, diuretic, anti-viral, anti-microbial, analgesic. This review give light up on biological and pharmacological activities of pyrimidine nucleus.
\end{abstract}

Keywords: Antioxidant, Antibacterial, Antifungal, Antiviral, Pyrimidine derivatives.

\section{INTRODUCTION}

Because of its different intrinsic biological properties Pyrimidine it become attractive for researcher in medicinal chemistry field $^{1}$, pyrimidines are used as Mycobacterium tuberculosis ${ }^{2}$, antioxidants ${ }^{3}$, antidiabetics ${ }^{4}$. Heterocycles which contain pyrimidopyrimidine have therapeutic properties ant allergic ${ }^{5}$, antioxidant ${ }^{6,7}$, antiviral ${ }^{8}$, antihistaminic ${ }^{9}$, cytostatic, immunomodulating ${ }^{10-12}$ herbicidal $^{13}$, anticonvulsant ${ }^{14}$ activities. pyrimidines exhibit antimicrobial activities such as fungicidal ${ }^{15}$, antitoxoplasma ${ }^{16}$, antimalarial ${ }^{17,18}$, antibacterial ${ }^{19,20}$, antifilerial $^{21}$ antileishmanial ${ }^{22,23}$, pyrimidine
(Fig. 1) broxuridine (I)-antiviral and brodimoprim (II)-respiratory tract and ear infections, trimethoprin (III)-antibacterial, antifungal flucytosine (IV),--liver disorder by orotic acid $(\mathrm{V})^{24}$.

Pyrimidine nucleus act as antimicrobial agent ${ }^{25}$ so they are important chemicals in agricultural and drugs.

Pyrimidines comprise important interesting group of antibacterial drugs, which have made a major impact on the field of antibacterial chemotherapy particularly in the past few years. Pyrimidine nucleus act as chemotherapeutic agents and exhibit anticancer activities ${ }^{26}$.

This is an Open Access article licensed under a Creative Commons license: Attribution 4.0 International (CC- BY). Published by Oriental Scientific Publishing Company @ 2018

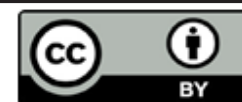


<smiles></smiles><smiles>COc1cc(Cc2cnc(N)nc2N)cc(C(C)=O)c1C(C)(C)C</smiles>

II Antibacterial<smiles>COc1cc(Cc2cnc(N)nc2N)cc(OC)c1Br</smiles>

II respiratory tract and ear infection<smiles>Nc1nc(=O)[nH]cc1F</smiles>

IV Antifungal<smiles>O=C(O)c1cc(=O)[nH]c(=O)[nH]1</smiles>

Fig. 1. Pyrimidine compounds that show pharmacological activity

Synthesis and biological activities of pyrimidine derivatives

Reaction of diazonium salt (1) and (2) in solution of $\mathrm{NaOH}$ yield the corresponding (3) which react with sulphonamide derivatives diazonium salt give compound (4 a-c) (Scheme $1)^{27}$, compounds (4b) and (4c) exhibit good results against anticancer and antifungal efficacies,
Gram-negative and gram positive respectively also both pyrimidine derivatives azo dyes and thiazolyl azo dyes derivatives displayed good properties on polyester fabrics, but thiazolyl azo dyes derivatives exhibit good properties than pyrimidine derivatives azo dyes ${ }^{27}$. sulphonamidediazobenzene derivatives exhibit pharmacological activities so it used as nontextile ${ }^{27}$.

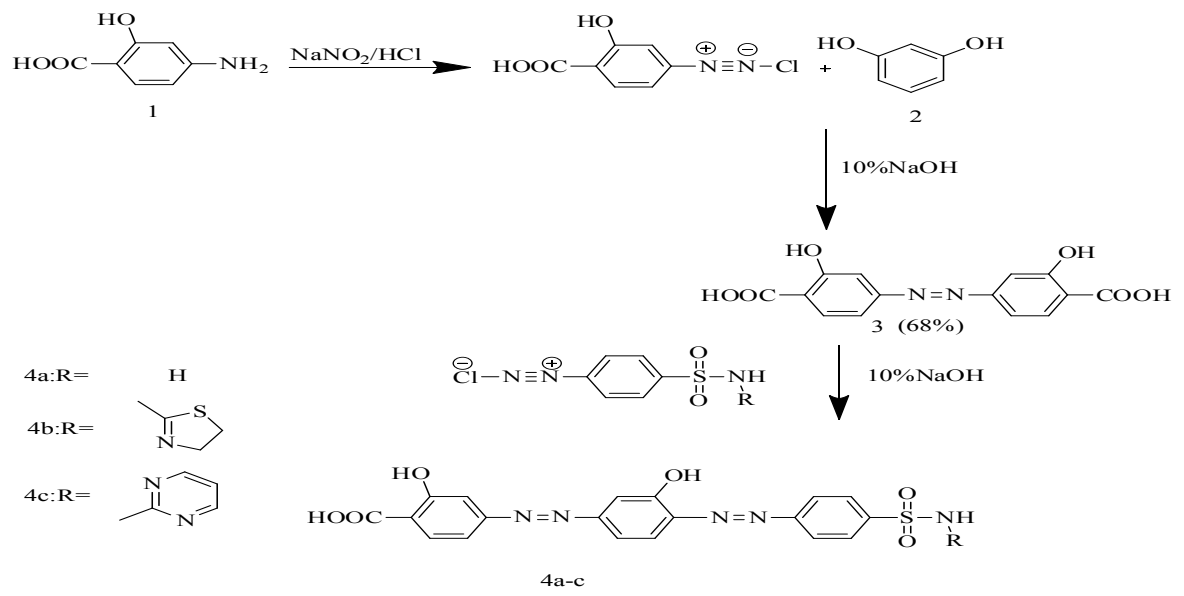

Scheme 1: Synthesis of diazobenzene dyes (4a-c), 4a (81\%), 4b (77\%), 4c (79\%).

Treatment paracetamol(5) with 2,3-di chlorobenzaldehyde(6) in solution of $\mathrm{KOH}$ at $298 \mathrm{k}$ afford chalcones(7). Reaction of chalcones (7) with urea and potassium hydroxide in methyl alcohol yield the corresponding(8) Also treatment of chalcone(7) with Thiourea and $\mathrm{KOH}$ in methyl alcohol give compound(9), treatment of chalcone (7) and hydrazine monohydrate in $\mathrm{AcOH}$ provide the corresponding(10), the product recrystallized with ethanol ${ }^{28}$.

Reaction of triazole(11) with (12 a) by using different solvent such as methanol/ $/ \mathrm{HCl}$, ethanol, acetic acid, there is no reaction but the reaction of mixture in DMF using reflux and heat in presence of potassium carbonate anhydrous provide triazolo pyrimidine(15a) or (18a).

The confirmation of (18a) was performed via reaction of (19) and malononitrile at the same condition provide the same sample of (18a). Treatment of triazole(11) with (12b) provide triazolo pyrimidine (18b). Also, mixing of (11) with (12c) give amino derivatives (18c). Another method for the preparation of $(\mathbf{1 8 b}, \mathbf{c})$ is the reaction of benzyl cyanide and cyanoacetate with (19), compound (18d) was synthesized by reaction of (12) with 
triazole (11). While reaction of (12e) with triazole (11) provide unsubstituted triazolo pyrimidine (18e). Triazolo pyrimidine (22) was synthesized via reaction of compound (20) with triazole (11), the reaction proceed by reflux in presence $\mathrm{DMF} / \mathrm{K}_{2} \mathrm{CO}_{3}$ via cyclization of (21).

Refluxing of compound (22) with substituted 1, 4-benzoquinone and acetonitrile (3eq.) via refluxing provide triazolopyrimidine (23) (Scheme 3 ). Cyclocondensation of $\beta$-enaminones (24a-c) with 11 and acetic acid via reflux give substituted pyrimidines, when equimolecular amount from compound (11) react with $\beta$-enaminones (24a) in presence of $D M F / \mathrm{K}_{2} \mathrm{CO}_{3}$ via refluxing for $2 \mathrm{~h}$ to provide isolated compounds (25a) and (26) in equal ratio ${ }^{29,30}$.

Compounds $(25 b, c)$ were prepared via treatment of $(\mathbf{2 4 b}, \mathbf{c})$ with compound $\mathbf{1 1}$ (cf. Scheme 4).

Pyrimidine derivatives (30a-n) (Table1) ${ }^{31}$ were prepared via treatment of three component (27), (28), (29) in ethanol.

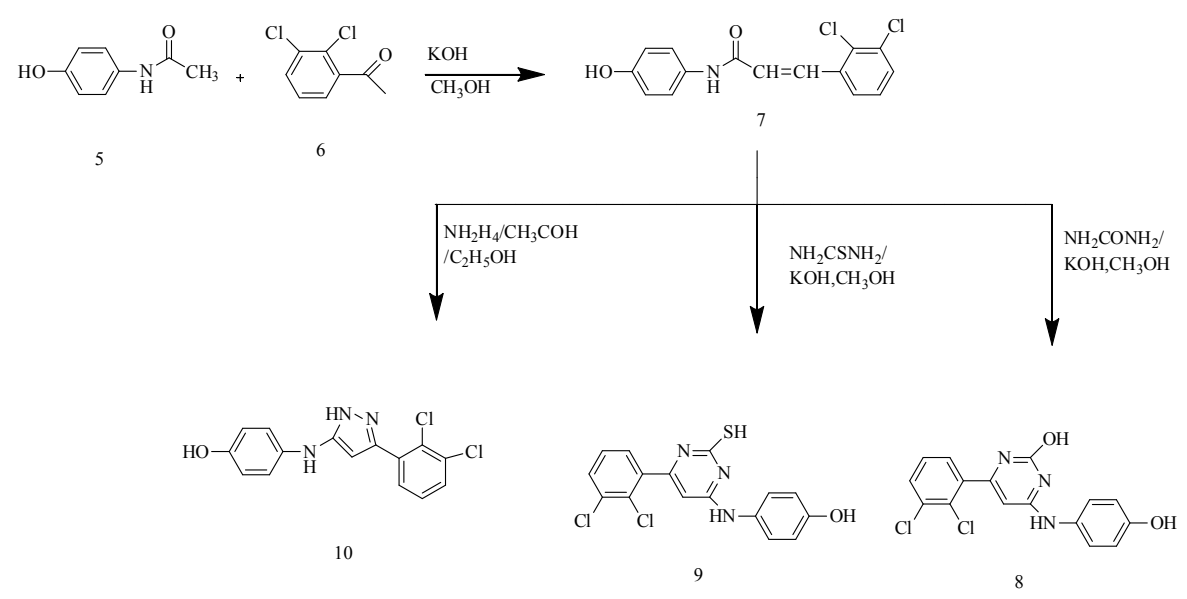

Scheme 2: Synthesis of pyrimidine (8) and (9)

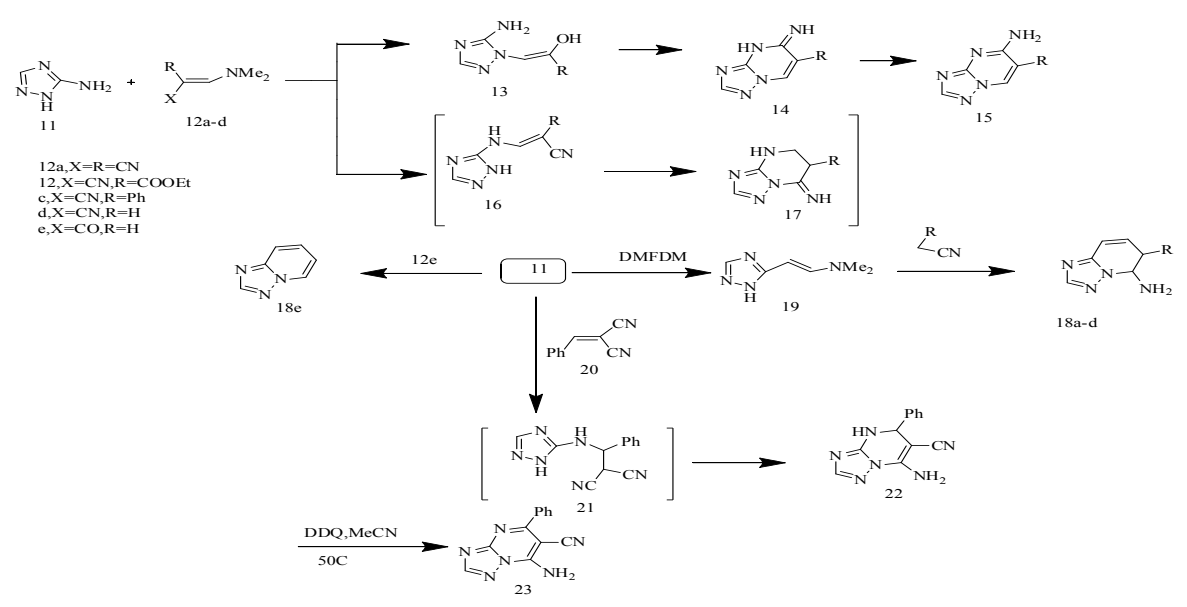

Scheme 3: Synthesis of pyrimidine 22 and 23

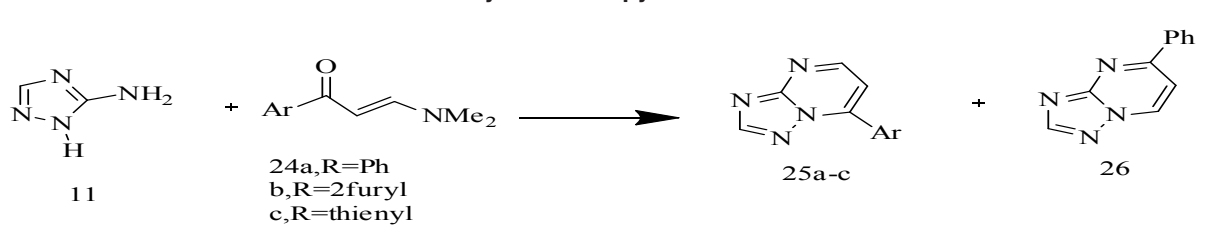

Scheme 4: Synthesis of pyrimidine derivatives $25 a-c$ and 26 
ELKANZI., Orient. J. Chem., Vol. 36(6), 1001-1015 (2020)

Table 1: Synthese of pyrimidines $(30 a-n)(30 a-n)^{31}$

\begin{tabular}{|c|c|c|}
\hline Compound No & Aldehyde & Structure \\
\hline \multicolumn{3}{|l|}{$30 a$} \\
\hline \multicolumn{3}{|l|}{$30 \mathrm{~b}$} \\
\hline \multicolumn{3}{|l|}{$30 c$} \\
\hline \multicolumn{3}{|l|}{$30 \mathrm{~d}$} \\
\hline \multicolumn{3}{|l|}{$30 \mathrm{e}$} \\
\hline \multicolumn{3}{|l|}{$30 f$} \\
\hline \multicolumn{3}{|l|}{$30 \mathrm{~g}$} \\
\hline \multicolumn{3}{|l|}{$30 \mathrm{~h}$} \\
\hline \multicolumn{3}{|c|}{$\mathrm{OHC}-$} \\
\hline \multicolumn{3}{|c|}{$\mathrm{OHC}$} \\
\hline \multicolumn{3}{|l|}{$30 \mathrm{k}$} \\
\hline \multicolumn{3}{|l|}{301} \\
\hline \multicolumn{3}{|l|}{$30 \mathrm{~m}$} \\
\hline $30 n$ & & \\
\hline
\end{tabular}




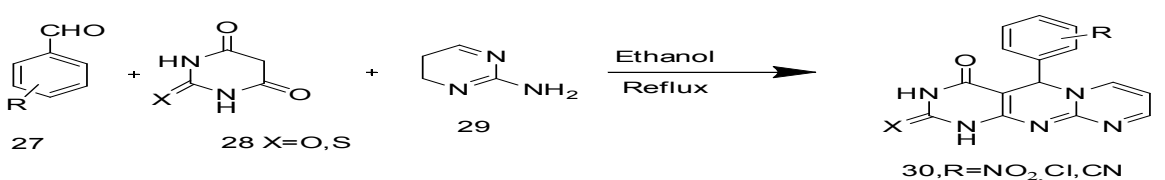

Scheme 5: Synthesis of pyrimidines (30a-n)

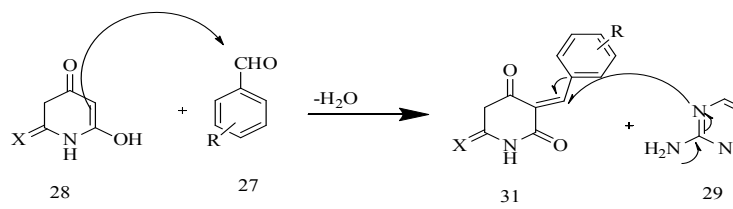

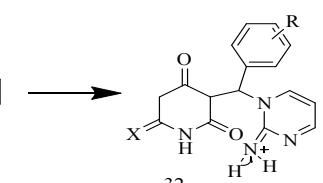

31

29

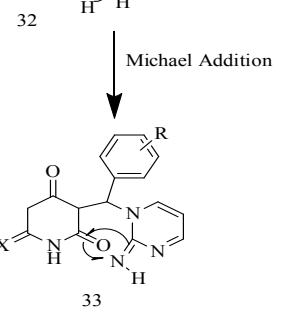<smiles>[R]c1ccc(C2C3=C(N=C4N=CC=CN42)NC([Y])CC3=O)cc1</smiles>

$$
-\mathrm{H} 2 \mathrm{O}
$$<smiles></smiles>

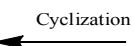

$\mathrm{X}=\mathrm{O}, \mathrm{S}$

Scheme 6: mechanism for synthesized pyrimidines (30a-n).

The condensation of thioxopyrimidine (35) with substituted aromatic aldehydes and $\alpha$ chloroacetic acid afford the corresponding thiazolopyrimidine derivatives (36a-h) (Scheme 7) ${ }^{32}$.

Treatment of 2-chloro- $N$-substitutedphenylacetamide $(\mathbf{3 7 a}-\mathbf{c})$ with thioxopyrimidine 35 and dimethyl formamide, potassium carbonate, provide (38a-c) and (39) obtained via reaction of compound (35) with p-toluene in presence of $\mathrm{K}_{2} \mathrm{CO}_{3}$ and DMF in stirring resulting $\mathrm{N}$-alkylation product. treatment of (35) with ethylacetoacetate and potassium carbonate anhydrous afford compound (40) which react with hydrazine hydrate and ethanol provide the corresponding compound(41) (Scheme 7) ${ }^{32}$.

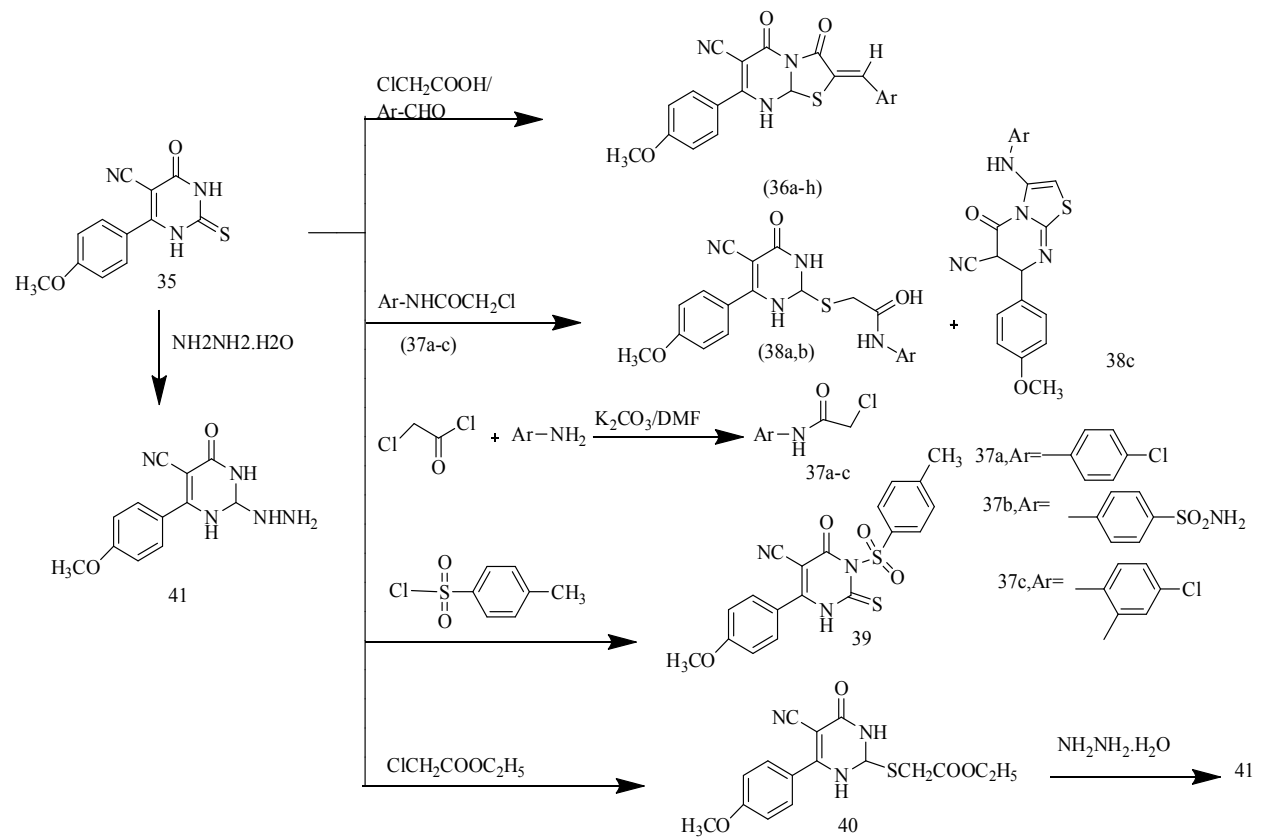

Scheme 7: Synthetic pathway of compounds (36-41) 
ELKANZI., Orient. J. Chem., Vol. 36(6), 1001-1015 (2020)

Table 2: The syntheses of compounds $(36 a-h)^{32}$
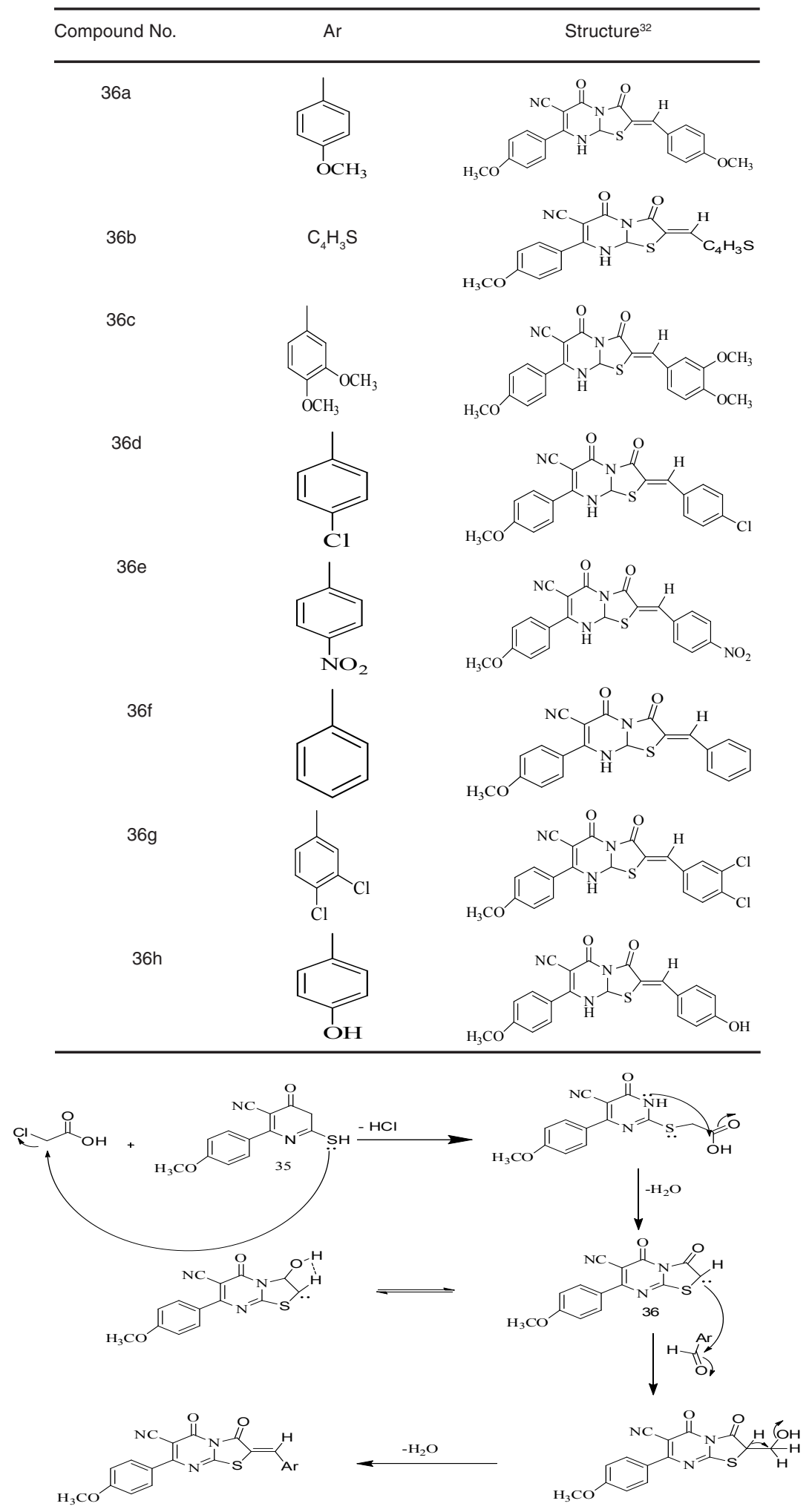

Scheme 8: Mechanism for synthesis of (36a-h) 

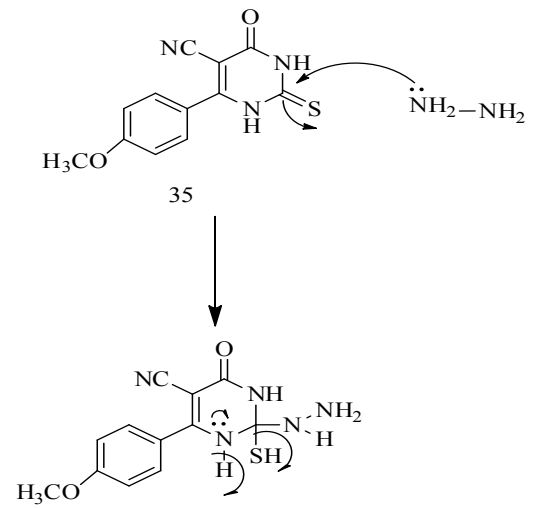<smiles>COC(=O)CSc1nc(-c2ccc(OC)cc2)c(C#N)c(=O)[nH]1</smiles>

40 $\mathrm{SN}_{2}$ arom.<smiles>COC(=O)CSC1(N)N=C(c2ccc(OC(C)=O)cc2)C(C#N)=C1C(N)=O</smiles><smiles>COc1ccc(-c2nc(NN)[nH]c(=O)c2C#N)cc1</smiles>

41

Scheme 9: Mechanism for compound (41)<smiles>COc1ccc(/C=N/Nc2nc(-c3ccc(OC)cc3)c(C#N)c(=O)[nH]2)cc1</smiles>

Scheme 10: Conversion of (41) to pyrimidine derivatives (42-45)

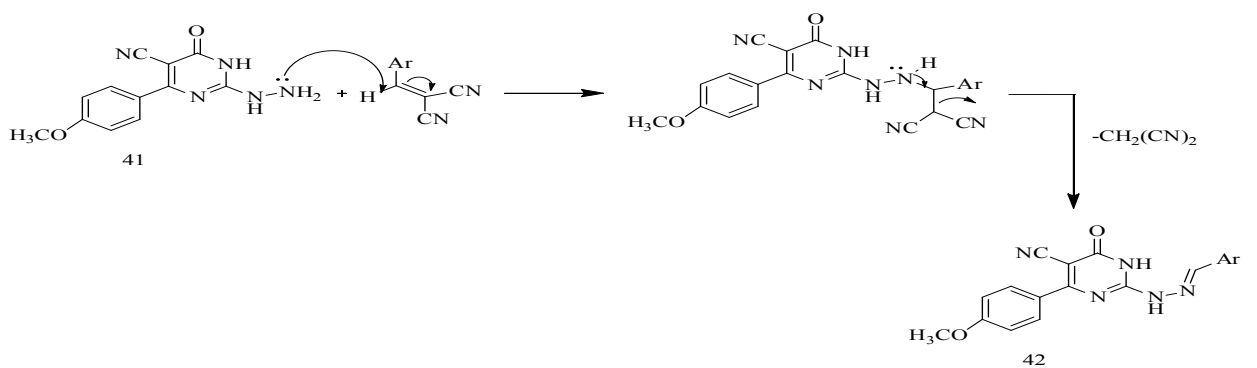

Scheme 11: Suggested mechanism for (42) 


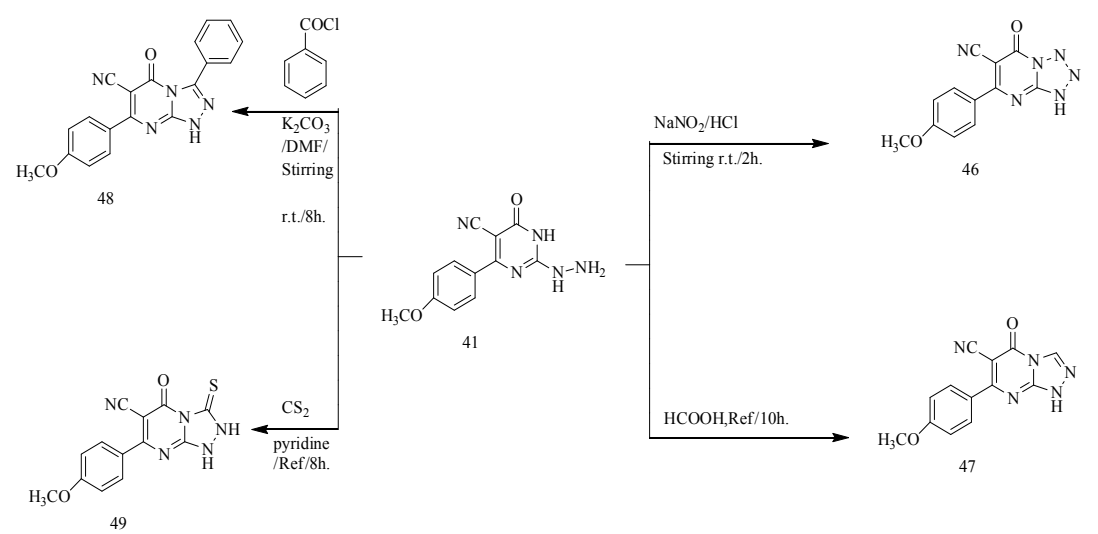

Scheme 12: Preparation of triazolo and tetrazolopyrimidinone derivatives (46-49)

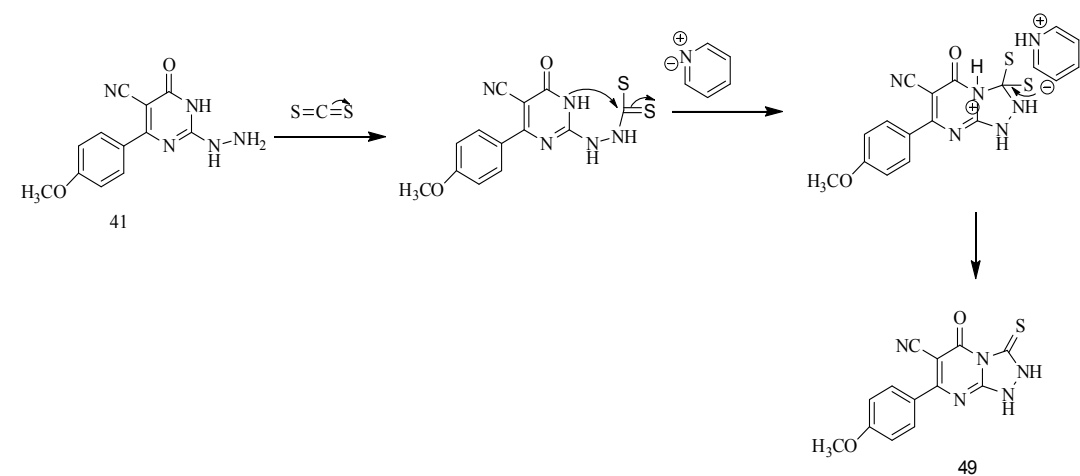

Scheme 13: mechanism (49)

Treatment of (35) with hydrazine hydrate affords hydrazino derivative (41). Treatment of (41) and arylidene provide the corresponding (42) (Scheme 11).

Synthesis of compounds (42-45) appears in (Scheme 10). Compound (42) obtained via reaction of $p$-methoxybenzaldehyde with hydrazine derivative $(\mathbf{4 1})^{32}$.

The acetyl derivatives $\mathbf{4 3}$ were obtained by reaction of compound (41) and acetic anhydride under reflux. Reaction of compound(41) with cyclopentanone in ethanol provide (44). Compound (45) was obtained by reaction of hydrazine derivative (41) with acetamide derivatives. Tetrazolopyrimidine (46) was obtained via diazotization of compound (41). Reaction of (41) with formic acid provide pyrimidines (47) (Scheme 6). Treatment of benzoyl chloride with compound (41) affords corresponding Triazolopyrimidone derivative (48). Reaction of
(41) and carbon disulfide in presence of pyridine provide triazolopyrimidone derivative $(49)^{32}$. The synthesized compounds of cyanothiouracil derivatives (36-49) were obtained from cyanothiouracils and dihydropyrimidine carbonitriles derivatives. Some of these compounds exhibit Potent activities, anticancer and Antimicrobial ${ }^{32}$.

Synthesis of (54a-I) proceed via twostep (Scheme 14$)^{33}$, the synthesis of $(54 a-I)$ via both methods microwave and conventional.in the conventional method substituted aldehydes (50a-I) treated with, malanonitrile (51), and 1, 3 dihydroxy benzene (52) afford the corresponding pyran derivatives (53a-I). Cyclization of pyrane derivatives $(53 a-I)$ by using nano catalyst provide $(54 a-I)$ this green method and highly efficient, Also the reaction occur without catalysts by using reflux for 8 hours. ${ }^{33}$.

The synthesized compounds exhibit antifungal, antioxidant and antibacterial effect ${ }^{33}$.

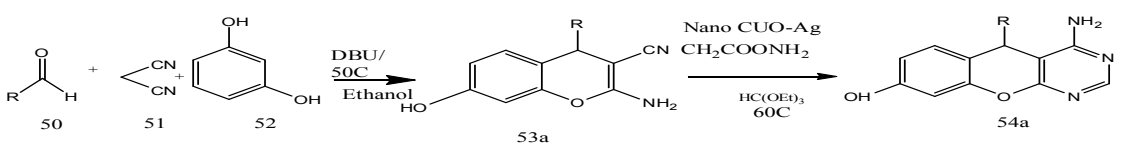

Scheme 14: synthesis of pyrano[2,3-d]pyrimidine (54a) 
ELKANZI., Orient. J. Chem., Vol. 36(6), 1001-1015 (2020)

Table 3: Syntheses of pyrano pyrimidine derivatives $(54 a-I)^{33}$

\begin{tabular}{|c|c|c|}
\hline Compound No. & $\mathrm{R}$ & Structure \\
\hline \multicolumn{3}{|l|}{$54 a$} \\
\hline \multicolumn{3}{|l|}{$54 \mathrm{~b}$} \\
\hline \multicolumn{3}{|l|}{$54 c$} \\
\hline \multicolumn{3}{|l|}{$54 d$} \\
\hline \multicolumn{3}{|l|}{$54 \mathrm{e}$} \\
\hline \multicolumn{3}{|l|}{$54 f$} \\
\hline \multicolumn{3}{|l|}{$54 \mathrm{~g}$} \\
\hline \multicolumn{3}{|l|}{$54 \mathrm{~h}$} \\
\hline \multicolumn{3}{|l|}{$54 \mathrm{i}$} \\
\hline \multicolumn{3}{|l|}{$54 j$} \\
\hline \multicolumn{3}{|l|}{$54 \mathrm{k}$} \\
\hline \multicolumn{3}{|l|}{541} \\
\hline
\end{tabular}


<smiles>[R]c1ccccc1C=O</smiles>

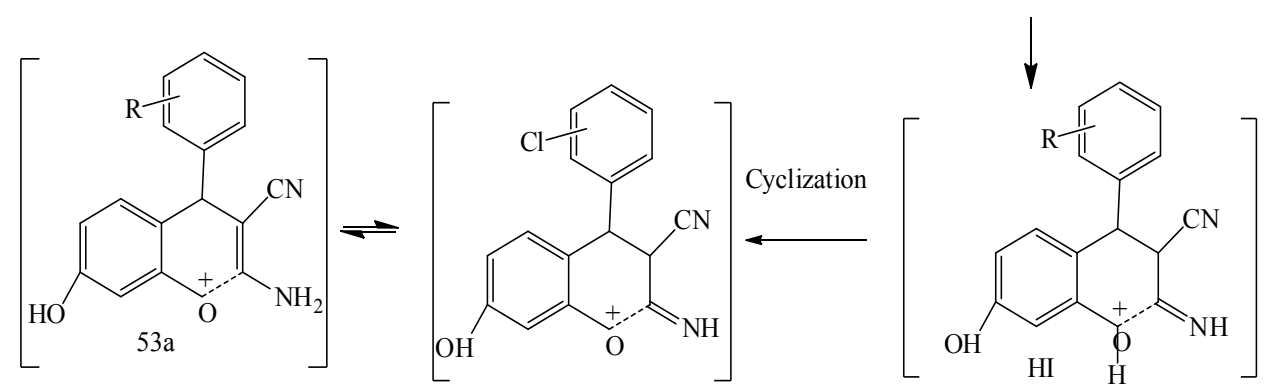

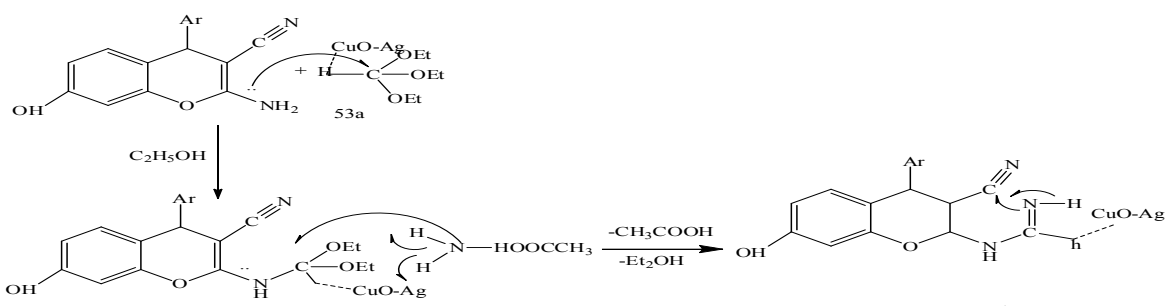

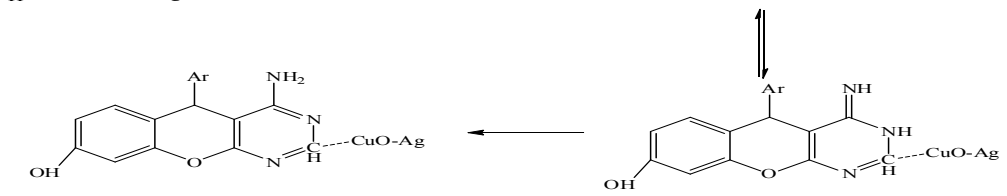

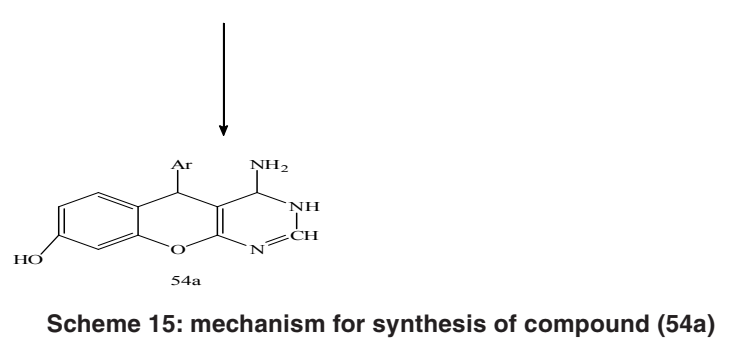

Pyrimidine (58) was prepared by in the absence of catalyst lead to there is no treatment of methylthiopyrimidinone (55) with formation of product formed after $3 \mathrm{~h}$ the reaction bromomethylacetylene (56) in $\mathrm{K}_{2} \mathrm{CO}_{3} / \mathrm{DMF}$ at room give maximum of the yield when use Cul/Mg-Al-LDH temperature (Scheme 16) ${ }^{34}$. catalyst $[28$, this method was easy, clean reaction, Treatment of pyrimidine (57) and (59a) short reaction time and high yield ${ }^{34}$.

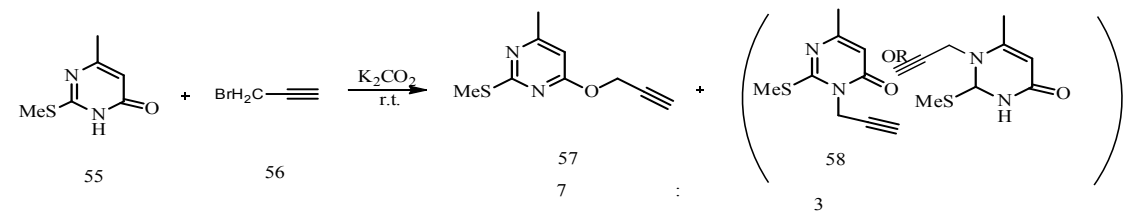

Scheme 16: Synthesis of compound 57 and 58 
<smiles>C#CCOc1cc(C)nc(SC(C)(C)C)n1</smiles>

(C)

Scheme 17: Proposed mechanism for synthesis of pyrimidine derivatives (60)

Table 4: Syntheses of pyrimidine derivatives $(60 \mathrm{a}-\mathrm{i})^{34}$

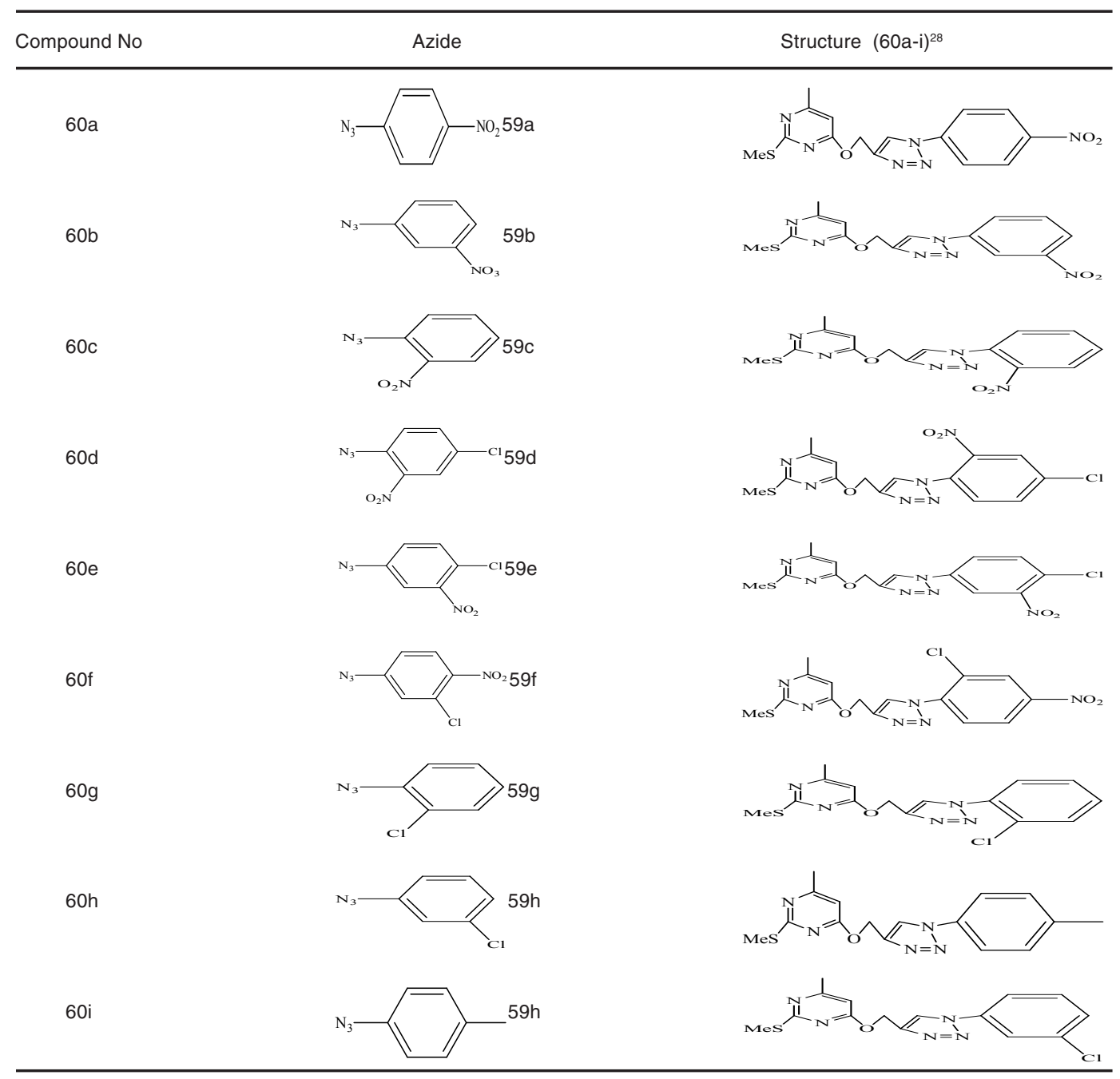

Reaction of compound (63) with $\mathbf{6 4 , 6 6 , 6 8}$ considered as a key for synthesis of different afford the corresponding thioxypyrimidine (67) pyrimidine derivatives ${ }^{35}$. The formation of compound and pyridinethione (69) these compounds was (63) indicated in (Scheme 18) ${ }^{36}$. 
Compound (65) (Scheme 18) (37 $^{37}$ was prepared by treatment of chalcone (63) with thiourea (64) compound (67) was prepared via treatment of chalcone (63) and dihydropyrimidinone (66) (Scheme 18) ${ }^{38}$. the compound (69) was prepared by treatment of 2-cyanoethanethioamide (68) with chalcone (63) in diaoxane and piperidine catalyst at reflux the reaction proceed via cyclocondensation reaction (Scheme 18) ${ }^{39}$.

Reaction of (65) or (67) with the appropriate nitrilimines (71) afford the corresponding triazole compound, the nitrilimines (71) prepared by treatment of hydrazonoyl chlorides $(\mathbf{7 0})^{40}$ With triethylamine (TEA). Triazolo pyrimidine (75a) (Scheme 19) was prepared by reaction of hydrazonylchloride $(\mathbf{7 0 a})$ with pyrimidine-2(1H)thione (65) at reflux. In addition, reaction of hydrazonyl chlorides 70b-d with compound 65 provide triazolo pyrimidines (75b-d) (Scheme 19).

Initial alkylation of (65) to provide thiohydrazonate (72) and then cyclization to provide the spiro-intermediate (73) and rearrangement occur ${ }^{11}$ provide corresponding (75) via (74) (Scheme 19).

Also treatment of thioxopyrido[pyrimidinone (67) with hydrazoe (70a-c) provide triazolopyrimidines (76a-c) (Scheme 19) ${ }^{38}$, thienopyridine (78) (Scheme 20) was synthesized by treatment of 2-dihydropyridine-3-carbonitrile (69) with 2-chloroacetamide (77) in sodium ethoxide at reflux ${ }^{42}$. thienopyrimidinone derivative (80) (Scheme $20)^{42}$ was prepared by reaction of thieno[2,3-b] pyridine-2-caboxamide derivative (78) with (79). Also, 2-carboxamide derivative (78) treated with both (81), (83a) and (83b) to give compounds (82) and $(\mathbf{8 4 a}, \mathbf{b}, \mathbf{)})($ Scheme 20 ). pyridotpyrimidinone (86)(Scheme 21$)^{42}$ was synthesized by reaction of thienopyrimidinone (80) and iodomethane (85) in ethanolic sodium ethoxide. Preparation of fused triazole was proceed by treatment of (86) with hydrazonyl chlorides $(\mathbf{7 0})^{43}$. triazolopyrimidinone derivative (88a) was synthesized by reaction of compound (86) with hydrazonyl chloride (70a) in dioxane and triethylamine at reflux, to provide (87) and then loss methane thiol provide (88a) (Scheme 21). Also, compound (86) treated with $(\mathbf{7 0 b}-\mathbf{d})$ to provide triazolopyrimidinones $(\mathbf{8 8 b}-\mathbf{d})$ (Scheme 21). Treatment of 2-thioxopyridothienopyrimidin$4(1 \mathrm{H})$-one derivative $(\mathbf{8 0})$ with hydrazonyl chloride $70 \mathrm{a}$ in dioxane and triethylamine at reflux afford the corresponding compound (88a).

$(\text { Scheme } 21)^{35}$. the newly pyrimidines was exhibit In vitro antimicrobial activities ${ }^{35}$.

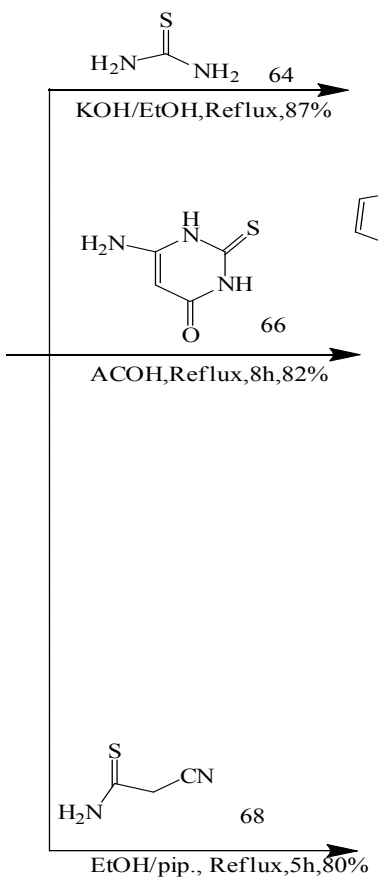<smiles>C=C(C)C1=NC2NC(=S)NC(=O)C2C(c2cccs2)=C1</smiles><smiles>C1CCC1</smiles><smiles>N#Cc1c(-c2ccc3c(c2)OCO3)cc(-c2cccs2)[nH]c1=O</smiles>

Scheme 18: Preparation pyrimidinone (69) 


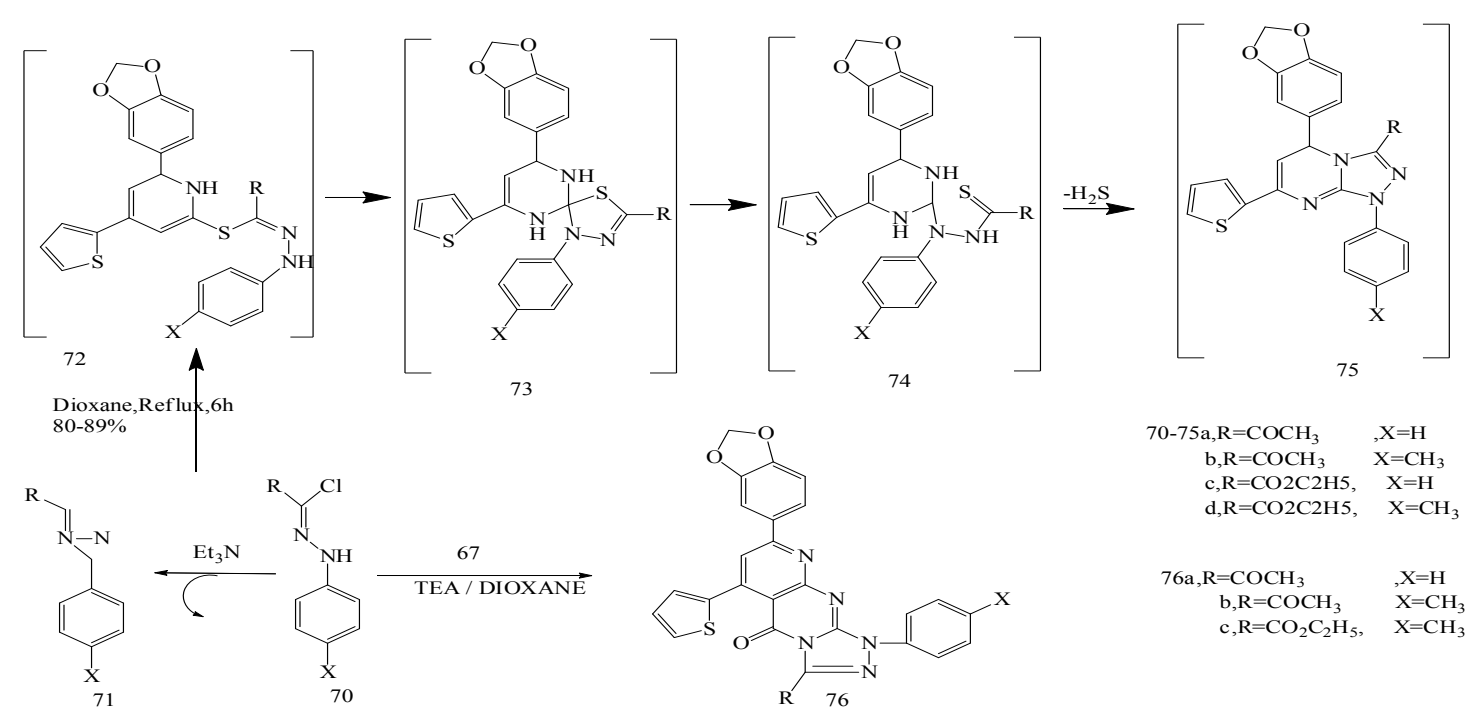

Scheme 19: Preparation] triazolopyrimidines (75) and (76)
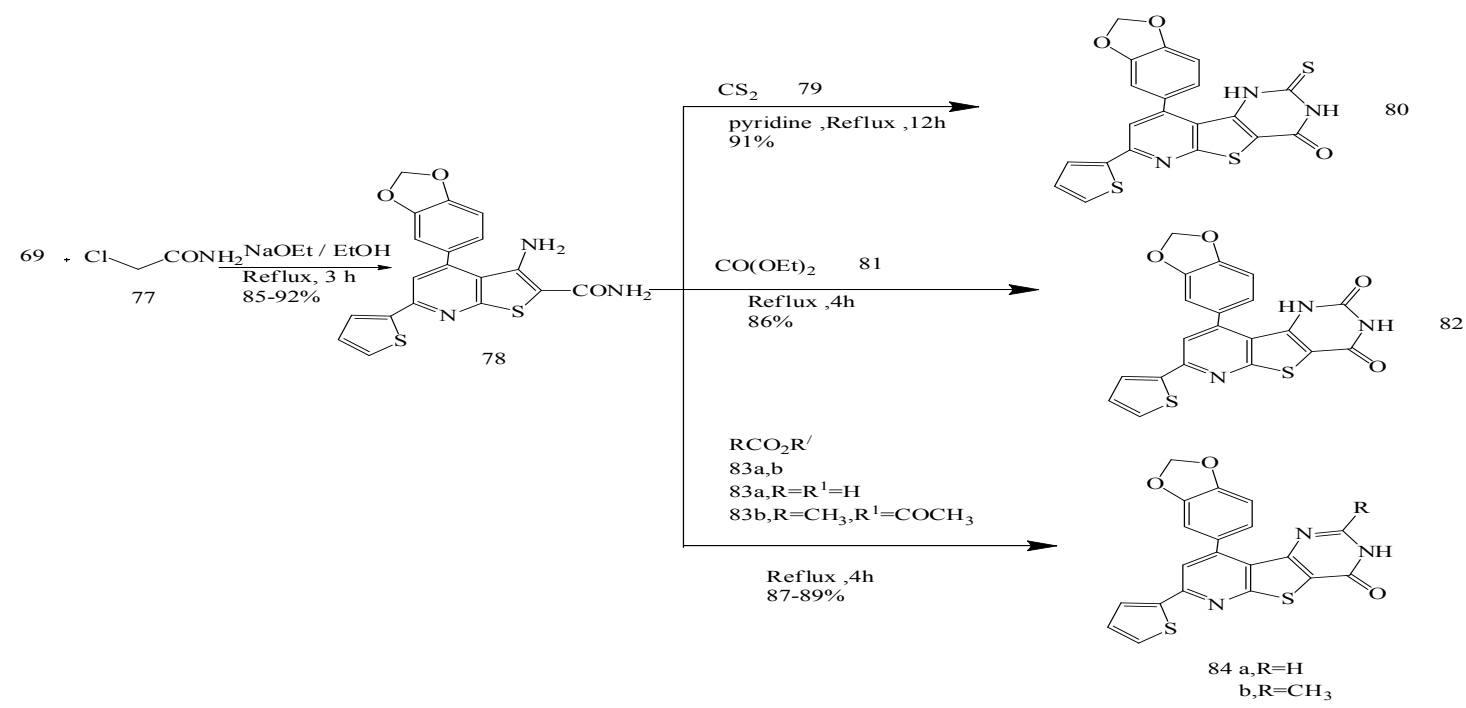

Scheme 20: preparation pyrimidinones (80), (82) and (84a, b)
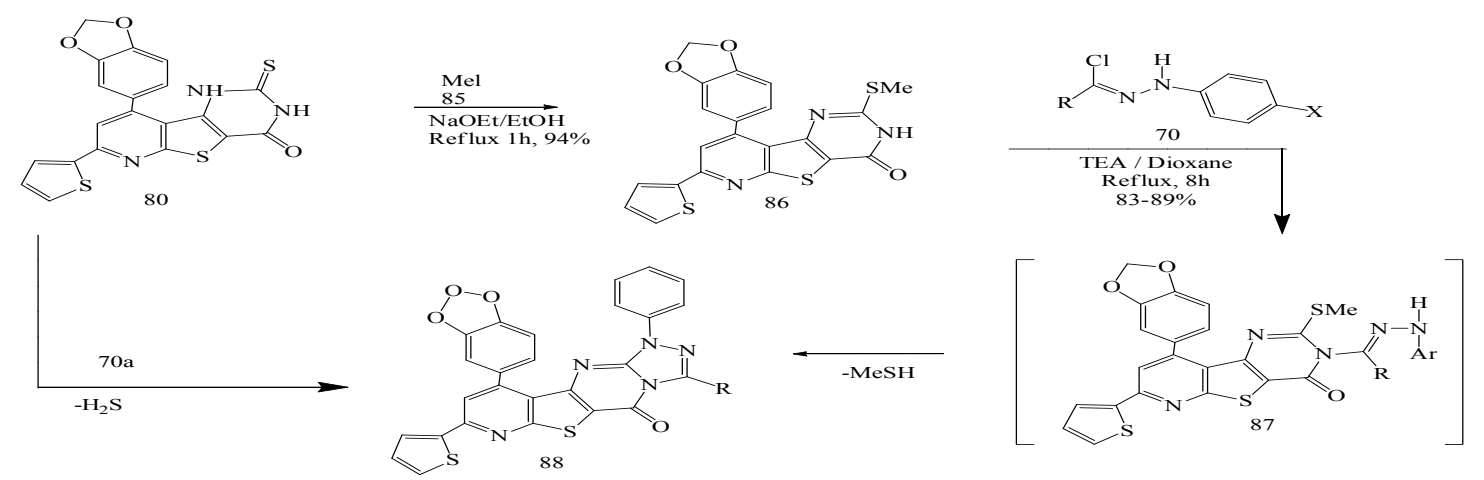

$70,87,88 \mathrm{a} ; \mathrm{R}=\mathrm{COCH}_{3}, \mathrm{X}=\mathrm{H} ; \mathrm{b} ; \mathrm{R}=\mathrm{COCH}_{3}, \mathrm{X}=\mathrm{CH}_{3} ; \mathrm{c} ; \mathrm{R}=\mathrm{CO}_{2} \mathrm{C}_{2} \mathrm{H}_{5}, \mathrm{X}=\mathrm{H} ; \mathrm{d} ; \mathrm{R}=\mathrm{CO}_{2} \mathrm{C}_{2} \mathrm{H}_{5}, \mathrm{X}=\mathrm{CH}_{3}$

Scheme 21: Preparation triazolopyrimidinones (88) 
ethyl 3-amino-2-cyano-6-hydroxy-7, 12dioxo-2, 7, 12, 12a-tetrahydro-1H-benzo[g]pyrimido [1, 2-a]quinoline-5-carboxylate 90 was prepared by reaction of alkylidenemalononitrile derivatives with ethyl 2-amino-4-hydroxy-5, 10-dioxo-1, 5, 10, 10atetrahydrobenzo[g]quinoline-3-carboxylate 89 , the pyrimido quinolone derivatives have photodiode applications ${ }^{44}$.

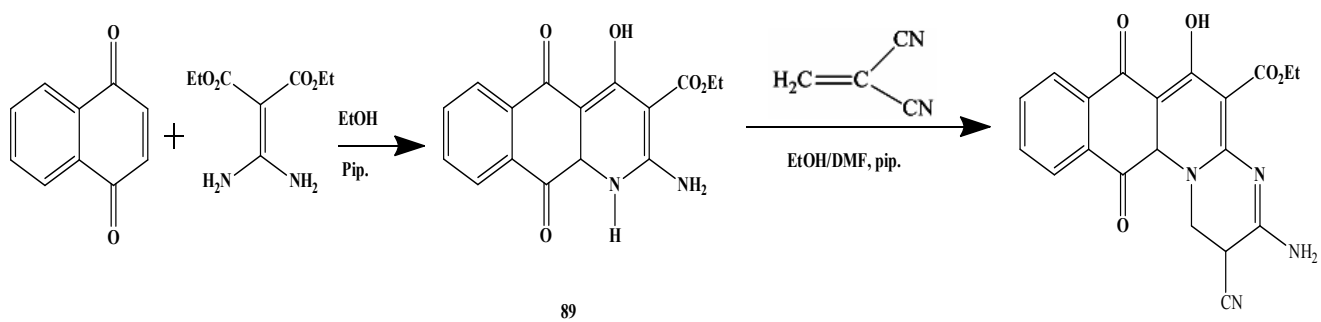

Scheme 22. Synthesis of pyrimido quinolone derivatives (90)

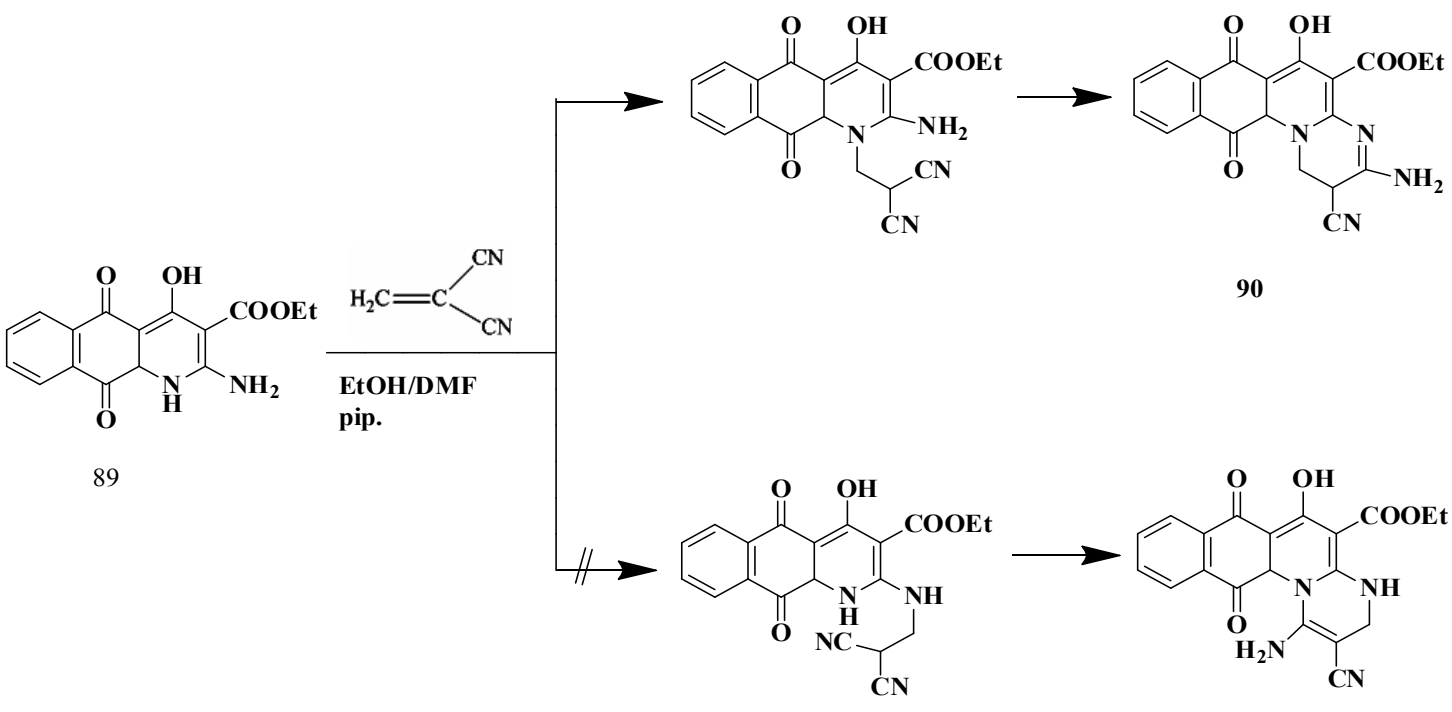

Scheme 23: Synthetic pathway for the pyrimido quinolone derivatives

\section{CONCLUSION}

The current study gives a portrayal of the biological and natural significance of heterocyclic related pyrimidine nucleus, these pyrimidine unit exhibited significant and assorted organic properties, the examined pyrimidine derivatives prepared by cyclocondensation reaction, also through reaction of chalcone with different 1, 3-dinucleophiles. Pyrimidine derivatives that have biological activities.

\section{ACKNOWLEDGMENT}

The author grateful to Jouf University, Saudi Arabia and Aswan University, Aswan, Egypt is gratefully acknowledged.

\section{Conflicts of Interest}

The author declares no conflict of interest.

\section{REFERENCES}

1. Abdel-Rahman R.; El-Mahdy K. Heterocycles., 2012, 85, 2391-2414.

2. Bacelar, A.H.; Carvalho, M.A.; Proença, M.F. Eur. J. Med. Chem., 2010, 45, 3234-3239.

3. De la Cruz J. P.; Carrasco T.; Ortega G. ; De la Cuesta F. S. Lipids., 1992, 27, 192-194.
4. $\quad$ Fang Y.; Xu J.; Li Z.; Yang Z.; Xiong L.; Jin Y.; Wang Q.; Xie S.; Zhu W.; Chang S. Bioorg. Med. Chem., 2018, 26, 40804087.

5. Abu-Hashem A. A.; Youssef M. M.; Hussein H. A. R. J. Chin. Chem. Soc., 2001, 58, 41-84. 
6. Rahaman S. A.;PasadY. R.; Kumar P.; Kumar B. SaudiPharm. J., 2009, 17, 255-258.

7. Nezu Y.; Miyazaki M.;Sugiyama K.;Kajiwara I. Pestic. Sci., 1996, 47, 103-113.

8. Machon Z.; Cieplik J. Pol. J. Pharmacol., 1988, 40, 201-208.

9. Agarwal A.; Srivastava K.; Puri S. K.; Chauhan P. M. S Bioorg. Med. Chem., 2005, 13, 46454650.

10. Mohamed N. R.; El-Saidi M. M.; Ali Y. M.; Elnagdi M. H., Bioorg. Med. Chem., 2007, 15, 6227-6235.

11. Juby P.F.; Hudyma T.W.; Brown M.; Essery J.M.; Partyka R.A. J. Med. Chem., 1979, 22, 263-269.

12. Gupta A. K.; Kayath S. H. P.; Singh A.;Sharma G.; Mishra K. C., Indian J. Pharm., 1994, 26, 227-228.

13. Stocks P. A.; Raynes K. J.; Bray P. G.; Park B. K.; Neill P. M.; Ward S. A., J. Med. Chem., 2002, 45, 4975-4983.

14. Abu-Hashem A. A.; El-Shehry M. F.; Badria F. A. Acta Pharm., 2010, 60, 311-323.

15. Gangjee A; Mavandadi F; Queener S F. J. Med. Chem., 1997, 40, 1173-1177.

16. Torrence P. F.; Fan X.; Zhang X.; Loiseau P. M. Bioorg. Med. Chem. Lett., 2006, 16, 50475051.

17. Katiyar S. B.; Bansal I.; Saxena J.K.; Chauhan P. M. S., Med. Chem. Lett., 2005, 3(15), 47-50.

18. Ren Q.; Cui Z.; He H.; GuY. J. Fluorine Chem., 2007, 128, 1369-1375.

19. Saudi, M.N.S.; Gaafar, M.R.; El-Azzouni, M.Z. Med Chem Res., 2008, 17, 541.

20. Sunduru N.; Agarwal A.; Katiyar S.B.; Nishi, Goyal N.; Gupta S.; Chauhan P.M. Bioorg Med Chem., 2006, 14, 7706-7715.

21. Ali A.; Taylor G. E.; Ellsworth K.;Harris G.; Painter R.; Silver L. L.; Young K. J. Med. Chem., 2003, 46, 1824-1830.

22. Selvam T.P.; James C.R.; Dniandev P.V.; Valzita S.K. Res Pharm., 2012, 2, 1-9.

23. Patil, S.A.; Patil, R.; Pfeffer, L.M.; Miller, D.D. Future Med. Chem., 2013, 5, 1647-1660.

24. Kemnitzer W.; Kasibhatla S.; Jiang S.; Zhang H.; Zhao J.; Jia S.; Xu L.; Crogan-Grundy C.; Denis R.; Barriault N.; Vaillancourt L.;Charron S.; Dodd J.; Attardo G.;Labrecque D.; Lamothe S.; Gourdeau H.; Tseng B.; Drewe
J.; Cai S.X. Bioorg Med Chem Lett., 2005, 15, 4745-4751.

25. Mallikarjunaswamy C.; Mallesha L.; Bhadregowda D.G.; Othbert P., Arab. J. Chem., 2017, 10, S484-S490.

26. Sridhar S.; Rajendra P.Y.; Dinda S. C. IJPSR., 2011, 2, 2562-2565.

27. Sraa A.M., Pigment \& Resin Technology., 2019, 48, 397-403.

28. Zaied A. M.; AL-Qadisiyah Journal of pure Science., 2018, 23, 141.

29. Petrich S. A.; Lisa Z. Q.; Santigo M.; Gupton J.T.; Sikorski J. A. Tetrahedron., 1994, 50, 12113.

30. Sirakawa K.; J. Pharm. Soc. Japan., 1960, 86, 956.

31. Priyanka T. P.; Warekar P. P.; Kirti T. P.; Dattatraya K. J.; Govind B. K.; Prashant V. A.; Res Chem Intermed., 2017, 43, 4103-4114.

32. Mohamed M. M.; Ali K. K.; Eslam M. A.; ElNaggar A. M. Synth. Commun., 2017, 47, 1441-1457.

33. Sreelakshmi P.; Mahammad S. S.; Murali S.; Subbarao Y.; Vedasree N.; Apparao C.; Suresh R. C.; J. Chin. Chem. Soc., 2019, 1-16.

34. Fatemeh R.; Mohammad B.; Hossein N.-Is.; Bahram B.; Soheila N., J. Heterocyclic Chem., 2020, 57, 565-574.

35. Sherif M. H. S.; Ahmed A. M. A.; Ahmed E. M. M. J Heterocyclic Chem., 2020, 57, 590-605.

36. Jain V. K.; Rao J.T. Indian Drugs., 2004, 41, 334.

37. Gomha S. M.; Mohamed A. M.; Zaki Y. H.; Ewies M. M., Elroby S. A. J. Heterocyclic Chem., 2018, 55, 1147-1156.

38. Gomha S. M.; Abdalla M.; EL-Aziz M. A.; Serag N, Turk. J. Chem., 2016, 40, 484-498.

39. Shestopalov, A.M.; Nikishin, K.G.; Gromova, A.V.; Rodinovskaya, L.A. Russ. Chem. Bull., 2003, 52, 2203-2206.

40. Farag, A. M.; Algharib, M. S. Org. Prep. Proced. Int., 1988, 20, 521-526.

41. Holden C. M.; Greaney M. F. Chemistry A European Journal., 2017, 23, 8992-9008.

42. Litvinov, V.P.; Dotsenko, V.V.; Krivokolysko, S.G. Russ. Chem. Bull., 2005, 54, 864-904.

43. Abbas I.; Gomha S.; Elneairy M. A. A.; Elaasser M.; Mabrouk B. Turk. J. Chem., 2015, 39, 510-531.

44. Elkanzi N. A.A.; Farag A.A.M.; Roushdy N.; Mansour A.M. Optik., 2020, 216, 164882. 